\title{
EDITORIAL
}

\section{Daytime predictors of sleep-disordered breathing in neuromuscular patients to better schedule polysomnography}

\author{
F. Lofaso*,\#, B. Fauroux ${ }^{\top,+}$, D. Orlikowski* and H. Prigent*
}

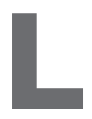

ong-term mechanical ventilation has improved survival and quality of life in patients with neuromuscular disorders (NMD) [1-4].

The 1999 consensus guidelines for the initiation of nocturnal mechanical ventilation [5] included criteria related to hypoventilation during sleep; namely symptoms suggesting hypercapnia during sleep and oxygen desaturation for a consecutive 5 mins. However, patients with NMD frequently under-report symptoms related to hypoventilation, which are also often nonspecific [6]. Moreover, the usefulness of oxygen saturation alone is limited because of the hyperbolic shape of oxyhaemoglobin dissociation curve, which may show minor oxygen dissociation in the presence of hypoventilation and reduced arterial oxygen tension. Another limit of these consensus guidelines [5] is that sleep apnoea syndrome, which is frequent in NMD populations [7], was not taken into account. Finally, establishing the diagnosis of sleep disorder breathing (SDB) is important, and the initial diagnostic polysomnography will also be useful in the patients' follow-up, as it will allow to evaluate the efficiency of mechanical ventilation on sleep parameters [8].

Previously, the randomised study of RAPHAEL et al. [9] showed increased mortality in noninvasive ventilation users compared with control subjects, in patients with Duchenne muscular dystrophy starting mechanical ventilation before occurrence of symptoms and/or of diurnal hypercapnia; this suggested that initiating mechanical ventilation this early in the disease was deleterious. However, at the time of the study, compliance and efficiency of mechanical ventilation setting during sleep were not verified [10]; moreover, the teams managing the ventilated patients may have had a false sense of security leading to the paradoxical effect on mortality observed by RAPHAEL et al. [9]. However, neuromuscular patients with nocturnal hypoventilation, detected

\footnotetext{
*Services de Physiologie, APHP, Hôpital Raymond Poincaré, Explorations Fonctionnelles, Réanimation Médicale, Rééducation Fonctionnelle, et Centre d'Investigation Clinique et d'Innovation Technologique, Garches, \#Pediatric Pulmonology Dept, Inserm U 955, Créteil, 'Pediatric Pulmonary Dept, APHP, Hôpital Armand Trousseau, and +Université Pierre et Marie CurieParis 6, Inserm UMR S-938, Paris, France.

CORRESPONDENCE: F. Lofaso, APHP, Hôpital Raymond Poincaré, Services de Physiologie Explorations Fonctionnelles, Réanimation Médicale, Rééducation Fonctionnelle, et Centre d'Investigation Clinique et d'Innovation Technologique (Inserm Unit 805), 92380 Garches, France. E-mail: f.lofaso@rpc.ap-hop-paris.fr
}

by a simple nocturnal transcutaneous carbon dioxide monitoring, are likely to develop diurnal hypercapnia and/or progressive symptoms within 2 yrs, which can be prevented if nocturnal mechanical ventilation is initiated and efficient [11]. Therefore, nowadays, the aim of the clinician is to detect the onset of the nocturnal hypoventilation and/or SDB in order to consider nocturnal mechanical ventilation initiation and to prepare the patient and his family for this treatment without precipitation [4]. It can also allow anticipation of the relative long delay usually necessary to obtain a baseline polysomnography before mechanical ventilation initiation.

To appropriately schedule polysomnography, some authors have tried to find daytime predictors of sleep hypoventilation and SDB in NMD patients [6, 12-15]. Generally these predictors relied upon respiratory function tests while symptoms questionnaires related to the quality of sleep were poorly predictive in these neuromuscular populations.

In this issue of the European Respiratory Journal, STEIER et al. [16] studied a questionnaire based on clinical signs of diaphragmatic dysfunction. The questionnaire was very simple, short to perform by the patient, easy to analyse and inexpensive. The authors obtained an excellent sensitivity and specificity for the diagnosis of SDB, whereas Epworth Sleepiness Scale and diaphragmatic strength measurements were not contributive.

STEIER et al. [16] included patients without severe paralysis of the limbs and the trunk; thus, they suggest considering the symptom as present when the handicap does not allow the patient to test the position (like bending forward) or the condition (like laying in a bath) which provokes the symptom. Another problem, underlined by the authors, is that immersion in water, the effect of which is evaluated in the questionnaire, aggravates patients with diaphragmatic weakness but can improve patients with abdominal paralysis. The study included a selected population who needed diaphragmatic exploration for a strong suspicion of diaphragmatic weakness. Nevertheless, these results are promising and it is now important to test this questionnaire in a wider neuromuscular population.

Should its sensibility and sensitivity be confirmed in a broader NMD population, this questionnaire could be associated to the usual simple respiratory function tests and the nocturnal recording of arterial oxygen saturation and transcutaneous arterial carbon dioxide tension in order to follow the yet 
unventilated neuromuscular population and to better identify the patients for whom polysomnography and therefore mechanical ventilation can be delayed without risk.

\section{STATEMENT OF INTEREST}

None declared.

\section{REFERENCES}

1 Ambrosino N, Carpene N, Gherardi M. Chronic respiratory care for neuromuscular diseases in adults. Eur Respir J 2009; 34: 444-451.

2 Ozsancak A, D'Ambrosio C, Hill NS. Nocturnal noninvasive ventilation. Chest 2008; 133: 1275-1286.

3 Windisch W. Impact of home mechanical ventilation on healthrelated quality of life. Eur Respir J 2008; 32: 1328-1336.

4 Simonds AK. Recent advances in respiratory care for neuromuscular disease. Chest 2006; 130: 1879-1886.

5 Clinical indications for noninvasive positive pressure ventilation in chronic respiratory failure due to restrictive lung disease, COPD, and nocturnal hypoventilation, a consensus conference report. Chest 1999; 116: 521-534.

6 Mellies U, Ragette R, Schwake C, et al. Daytime predictors of sleep disordered breathing in children and adolescents with neuromuscular disorders. Neuromuscul Disord 2003; 13: 123-128.

7 Chokroverty S. Sleep-disordered breathing in neuromuscular disorders: a condition in search of recognition. Muscle Nerve 2001; 24: 451-455.

8 Gonzalez MM, Parreira VF, Rodenstein DO. Non-invasive ventilation and sleep. Sleep Med Rev 2002; 6: 29-44.
9 Raphael JC, Chevret S, Chastang C, et al. Randomised trial of preventive nasal ventilation in Duchenne muscular dystrophy. French Multicentre Cooperative Group on Home Mechanical Ventilation Assistance in Duchenne de Boulogne Muscular Dystrophy. Lancet 1994; 343: 1600-1604.

10 Fanfulla F, Delmastro M, Berardinelli A, et al. Effects of different ventilator settings on sleep and inspiratory effort in patients with neuromuscular disease. Am J Respir Crit Care Med 2005; 172: 619-624.

11 Ward S, Chatwin M, Heather S, et al. Randomised controlled trial of non-invasive ventilation (NIV) for nocturnal hypoventilation in neuromuscular and chest wall disease patients with daytime normocapnia. Thorax 2005; 60: 1019-1024.

12 Hukins CA, Hillman DR. Daytime predictors of sleep hypoventilation in Duchenne muscular dystrophy. Am J Respir Crit Care Med 2000; 161: 166-170.

13 Lo Mauro A, D'Angelo MG, Romei M, et al. Abdominal volume contribution to tidal volume as an early indicator of respiratory impairment in Duchenne muscular dystrophy. Eur Respir J 2010; 35: $1118-1125$.

14 Ragette R, Mellies U, Schwake C, et al. Patterns and predictors of sleep disordered breathing in primary myopathies. Thorax 2002; 57: 724-728.

15 Toussaint M, Steens M, Soudon P. Lung function accurately predicts hypercapnia in patients with Duchenne muscular dystrophy. Chest 2007; 131: 368-375.

16 Steier J, Jolley CJ, Seymour J, et al. Screening for sleep-disordered breathing in neuromuscular disease using a questionnaire for symptoms associated with diaphragm paralysis. Eur Respir J 2011; 37: 400-405. 